\title{
Maternal factors associated with hyperglycemia in pregnancy and perinatal outcomes: a Brazilian reference center cohort study
}

\author{
Bianca F. Nicolosi ${ }^{1}$, Joice M. Vernini ${ }^{1}$, Roberto A. Costaㄹ, Claudia G. Magalhães ${ }^{2}$, Marilza V. C. Rudge ${ }^{1,2}$,
} José E. Corrente ${ }^{3}$, Jose G. Cecatti ${ }^{4}$ and Iracema M. P. Calderon ${ }^{1,2^{*}}$ (1)

\begin{abstract}
Background: While sufficient evidence supporting universal screening is not available, it is justifiable to look for specific risk factors for gestational diabetes mellitus (GDM) or hyperglycemia in pregnancy (HIP). The objective of this study is to identify independent risk factors for HIP and its adverse perinatal outcomes in a Brazilian public referral center.

Methods: We included 569 singleton pregnant women who were split into three groups by glucose status: GDM $(n=207)$, mild gestational hyperglycemia $(M G H ; n=133)$, and control $(n=229)$. Women who used corticosteroids or had a history of DM were excluded. HIP comprised both GDM and MGH, diagnosed by a $100 \mathrm{~g}$ - or 75 g-oral glucose tolerance test (OGTT) and a glucose profile at 24-28 weeks. Maternal characteristics were tested for their ability to predict HIP and its outcomes. Bivariate analysis (RR; $95 \% \mathrm{Cl}$ ) was used to identify potential associations. Logistic regression (RR adj; $95 \% \mathrm{Cl}$ ) was used to confirm the independent risk factors for HIP and its perinatal outcomes $(p<0.05)$.

Results: Age $\geq 25$ years $[1.83,1.12-2.99]$, prepregnancy BMI $\geq 25 \mathrm{~kg} / \mathrm{m}^{2}[2.88,1.89-4.39]$, family history of DM $[2.12,1.42-3.17]$ and multiparity $[2.07,1.27-3.37]$ were independent risk factors for HIP. Family history of DM [169, 1.16-2.16] and hypertension [2.00, 1.36-2.98] were independent risk factors for C-section. HbA1c $\geq 6.0 \%$ at birth was an independent risk factor for LGA [1.99, 1.05-3.80], macrosomia [2.43, 1.27-4.63], and birthweight Z-score > 2.0 [4.17, 1.57-11.10].

Conclusions: $\mathrm{MGH}$ presents adverse pregnancy outcomes similar to those observed in the GDM group but distinct from those observed in the control (no diabetes) group. In our cohort, age $\geq 25$ years, prepregnancy BMI $\geq 25 \mathrm{~kg} / \mathrm{m}^{2}$, family history of DM, and multiparity were independent risk factors for HIP, supporting the use of selective screening for this condition. These results should be validated in populations with similar characteristics in Brazil or other lowand middle-income countries.
\end{abstract}

Keywords: Hyperglycemia, Gestational diabetes, Pregnancy, Perinatal outcomes, Risk

*Correspondence: iracema.calderon@gmail.com

2 Department of Obstetrics and Gynecology, Botucatu Medical School, Unesp, Botucatu, SP, Brazil

Full list of author information is available at the end of the article

\section{Background}

Diabetes in pregnancy (DIP) and gestational diabetes mellitus (GDM), both of which are characterized by glucose intolerance first diagnosed in pregnancy, constitute a unique condition now named hyperglycemia

c) The Author(s) 2020. This article is licensed under a Creative Commons Attribution 4.0 International License, which permits use, sharing, adaptation, distribution and reproduction in any medium or format, as long as you give appropriate credit to the original author(s) and the source, provide a link to the Creative Commons licence, and indicate if changes were made. The images or other third party material in this article are included in the article's Creative Commons licence, unless indicated otherwise in a credit line to the material. If material is not included in the article's Creative Commons licence and your intended use is not permitted by statutory regulation or exceeds the permitted use, you will need to obtain permission directly from the copyright holder. To view a copy of this licence, visit http://creativeco mmons.org/licenses/by/4.0/. The Creative Commons Public Domain Dedication waiver (http://creativecommons.org/publicdomain/ zero/1.0/) applies to the data made available in this article, unless otherwise stated in a credit line to the data. 
in pregnancy (HIP). DIP is hyperglycemia diagnosed in early pregnancy using WHO diagnostic criteria for nonpregnant women; GDM is diagnosed in the second and third trimesters of pregnancy using IADPSG criteria based on the risk of adverse perinatal results [1-3]. GDM is the most common metabolic disorder that occurs during pregnancy, and it is associated with adverse shortand long-term effects on both the mother and offspring and an increased risk for future type 2 diabetes mellitus (T2DM), metabolic syndrome (MS) and cardiovascular disease (CVD) [4-7].

Milder forms of hyperglycemia that do not meet the diagnostic criteria for GDM but have adverse effects on the mother and offspring have been identified [8]. Over three decades ago, our public referral center found an association between the glucose profile (GP) test and the oral glucose tolerance test (OGTT) for the diagnosis of GDM. Regardless of normal OGTT, the abnormal GP test indicated hyperglycemia in some pregnant women; when hyperglycemia was untreated, the perinatal mortality rate was $4.16 \%$, which is similar to the rate observed in the GDM group and ten times greater than that observed in the nondiabetic control group. These cases are subjected to strict glucose control, similar to diabetes in pregnant women, and are classified as mild gestational hyperglycemia (MGH) $[9,10]$.

In our referral center, the IADPSG diagnostic protocol was adopted in August 2011, but the GP test was maintained in parallel with the $75 \mathrm{~g}$-OGTT. Even after this adoption, the prevalence of MGH was $17.3 \%$, and it was associated with LGA, macrosomia, first C-section, and hospital stay above 3 days $[1,11]$.

Brazil is one of the eight countries that accounts for $55 \%$ of the deliveries and $55 \%$ of the diabetes cases worldwide [3]. According to the Brazilian GDM diagnostic consensus, universal screening using FPG and 75-g OGTT must be applied in settings with technical and financial resources to identify $100 \%$ of cases; in settings with nonideal conditions, fasting plasma glucose (FPG) at the first prenatal visit may be used to screen for approximately $86 \%$ of GDM cases, and if the FPG levels are normal $(<92 \mathrm{mg} / \mathrm{dL})$ at the first prenatal visit, they should be reassessed at 24-28 weeks [12].

Although recent studies highlight a positive linear association between hyperglycemia in diagnostic tests and adverse outcomes for all glucose level exposures, there is no clear evidence regarding diagnostic tests or threshold effects. In low-income countries, the technical and financial conditions are limited, and it is important to investigate risk factors for GDM as an alternative to universal screening.

While better evidence supporting universal screening is not available and risk-based screening remains controversial and dependent on the specific characteristics of the population evaluated, it is justifiable to look for specific risk factors for GDM or other forms of hyperglycemia [13-17]. Therefore, the objectives of this study are (i) to compare the maternal and pregnancy characteristics and perinatal outcomes of women with different glucose statuses and (ii) to identify the independent risk factors for HIP and its respective adverse perinatal outcomes in a public tertiary referral center in Brazil.

\section{Methods \\ Study design and patients}

This is a cohort study that includes some previously published data [11]. The study was developed at the Botucatu Medical School/Unesp, a Brazilian obstetrical referral center. The original cohort from our Perinatal Diabetes Research Center (PDRC), with data prospectively collected and electronically stored at each prenatal visit and each event (diagnostic test for DMG or MGH, delivery, abortion, puerperium and, eventually, death), constituted the study database. Pairs of mothers and newborns assisted at our center between 1 January 2008 and 31 December 2014 were included. The inclusion criteria were as follows: underwent the diagnostic protocol for hyperglycemia in pregnancy $[9,10]$; had birth assistance at our referral center. The exclusion criteria were as follows: cases of multiple pregnancies; long-term use of corticosteroids; and a history of diabetes mellitus (overt DM, T1DM or T2DM).

\section{Simple size}

The sample size was calculated based on the frequency of maternal hyperglycemia (15-20\%) and LGA newborns $(12-14 \%)$ observed in our previous studies [10, 11]. Assuming a type II error of $20 \%$, a confidence level of $95 \%$, and $12 \%$ the minimum frequency, the desired sample size was estimated to be 554 pregnant women, including 277 without and 277 with hyperglycemia. We recruited 569 patients, including 229 control patients and $340 \mathrm{HIP}$ (GDM and MGH) patients.

\section{Diagnosis of hyperglycemia in pregnancy}

Prior to August 2011, the standard GDM diagnostic test was $100 \mathrm{~g}$-OGTT-fasting plasma glucose (FPG) below $5.3 \mathrm{mmol} / \mathrm{L}(95 \mathrm{mg} / \mathrm{dL}), 1 \mathrm{~h}$ postload plasma glucose less than $10.0 \mathrm{mmol} / \mathrm{L}(180 \mathrm{mg} / \mathrm{dL}), 2 \mathrm{~h}$ postload plasma glucose less than $8.6 \mathrm{mmol} / \mathrm{L}(155 \mathrm{mg} / \mathrm{dL})$, and $3 \mathrm{~h}$ postload plasma glucose less than $7.8 \mathrm{mmol} / \mathrm{L}(140 \mathrm{mg} / \mathrm{dL})$. GDM was confirmed when 2 values were equal to or above these limits [18]. After August 2011, the 75 g-OGTT was adopted-FPG between 5.1 and $6.9 \mathrm{mmol} / \mathrm{L}(92-125 \mathrm{mg} /$ $\mathrm{dL}$ ) or $1 \mathrm{~h}$ postload plasma glucose equal to or above 
$10.0 \mathrm{mmol} / \mathrm{L}(180 \mathrm{mg} / \mathrm{dL})$ or $2 \mathrm{~h}$ postload plasma glucose between 8.5 and $11.0 \mathrm{mmol} / \mathrm{L}(153-199 \mathrm{mg} / \mathrm{dL})[1,2,19]$.

The criteria for MGH diagnosis were normal $100 \mathrm{~g}$ - or $75 \mathrm{~g}$-OGTT and altered GP test, that is, fasting plasma glucose equal to or above $90 \mathrm{mg} / \mathrm{dL}(5.0 \mathrm{mmol} / \mathrm{L})$ or $2 \mathrm{~h}$ postprandial plasma glucose equal to or above $130 \mathrm{mg} /$ $\mathrm{dL}(7.2 \mathrm{mmol} / \mathrm{L})$. The GP test was performed over a oneday hospital stay with the women on a $2840 \mathrm{kcal}$ diet fractionated in five meals. Plasma glucose measurements were taken every 2 h between 8 a.m. and 6 p.m. $[9,10]$.

\section{Patient follow-up}

All patients included in this cohort started prenatal care before 20 weeks of gestation and underwent a hyperglycemia screening protocol between 24 and 28 gestational weeks $[9,10,18,19]$.

The pregnant women with normal OGTT and normal GP were classified as nondiabetic, had prenatal care in the public health system (primary level), and had childbirth assistance at the secondary or tertiary level (our referral center). Nondiabetic women who received birth assistance at our referral center and who agreed to participate in the study were included in the control group.

Immediately after the diagnosis, both MGH and GDM pregnant women were cared for the referral center by a multiprofessional team and underwent maternal glucose control, according to the ADA's recommendation. Lifestyle changes (diet and exercise) were first recommended, and this treatment was complemented by insulin therapy when glycemic goals were not achieved [20,21]. Oral hypoglycemic drugs are not recommended by ANVISA (the Brazilian Health Surveillance Agency) to be used in pregnancy, so they are not prescribed in our center.

The glucose control in pregnant women with GDM and MGH was monitored every 1 or 2 weeks by the GP test and was performed with an individual-specific diet. The respective glycemic mean $(\mathrm{GM}) \geq 120 \mathrm{mg} / \mathrm{dL}$ was defined as inadequate glucose control $[9,10]$.

\section{Maternal characteristics and perinatal outcomes}

The maternal baseline characteristics were defined by maternal age at enrollment, parity, number of prenatal visits, some indicators of socioeconomic status and habits, family history of DM (first degree) and prepregnancy hypertension $[18,19]$. Exercise was defined as the execution of planned, structured and repetitive corporal movements designed to improve one or more components of physical fitness, such as swimming, running and walking at an accelerated pace. The prepregnancy body mass index (BMI; $\left.\mathrm{kg} / \mathrm{m}^{2}\right)$ was calculated using the selfreported prepregnancy maternal weight; the pregnancy weight gain $(\mathrm{kg})$ was calculated by the difference between final pregnancy weight and prepregnancy maternal weight and was classified according to the prepregnancy BMI [22]. The glucose status was evaluated at the GDM screening (24-28 weeks) by 100 g- or 75 g-OGTT combined with the GP test $[1,2,9,10,18,19]$. Glycated hemoglobin (HbA1c) was evaluated later in pregnancy (36-38 weeks) or at birth in nondiabetic women. HbA1c levels $\geq 6.0$ or $\geq 6.5 \%$ were defined as markers for inadequate glucose control status and an increased risk of adverse perinatal outcomes [23].

The perinatal outcomes evaluated in this study were defined by the potential hyperglycemia influence and a $12-15 \%$ rate of missed data. At birth, the mode of delivery, gestational age (GA) and birthweight (BW) according to GA were assessed. The cephalic/abdominal perimeter ratio, ponderal index $\left[\mathrm{PI}=\mathrm{BW}(\mathrm{g}) /\right.$ height $\left.(\mathrm{cm})^{3}\right], \mathrm{BW} / \mathrm{GA}$ $\mathrm{Z}$-score, and respective cutoff values complemented the evaluation of excessive fetal growth [24, 25]. Newborn sex (male or female), Apgar scores, biochemical parameters of the umbilical cord blood, malformations, and some indicators of the neonatal period, including death until 28 days and hospital length of stay, were also considered. All reference parameters were used in accordance with the clinical protocol of the local perinatal unit.

\section{Data collection and statistical analysis}

For the current analysis, we used the database of the cohort study from our referral center [11]. According to the predefined period and the inclusion and exclusion criteria, data were input in a specific Excel software spreadsheet, audited, and underwent consistency checking. To compare the maternal and pregnancy characteristics and perinatal outcomes among the three different glucose status groups, namely, nondiabetes (ND), MGH and GDM, the Chi squared test or Fisher's exact test was used as appropriate. To evaluate the association of HIP with maternal and pregnancy characteristics and with adverse perinatal outcomes, two study groups were defined, namely, the HIP group (MGH and GDM) and the control group (Non-HIP), and the relative risks (RR) and $95 \%$ confidence intervals (CIs) were calculated in the bivariate analysis.

Finally, logistic regression analysis was performed with the adjusted $\mathrm{RR}\left(\mathrm{RR}_{\mathrm{adj}}\right)$ and $95 \% \mathrm{CI}$ to identify the independent risk factors. In the forward model, all significant maternal and pregnancy characteristics were used as independent predictors; HIP and significant perinatal outcomes were included as outcomes. For all tests, the statistical significance limit was $p<0.05$.

\section{Results}

The study flowchart is shown in Fig. 1. A total of 796 pregnant women were assessed for eligibility; of these, 589 were selected for data consistency checking, and 20 


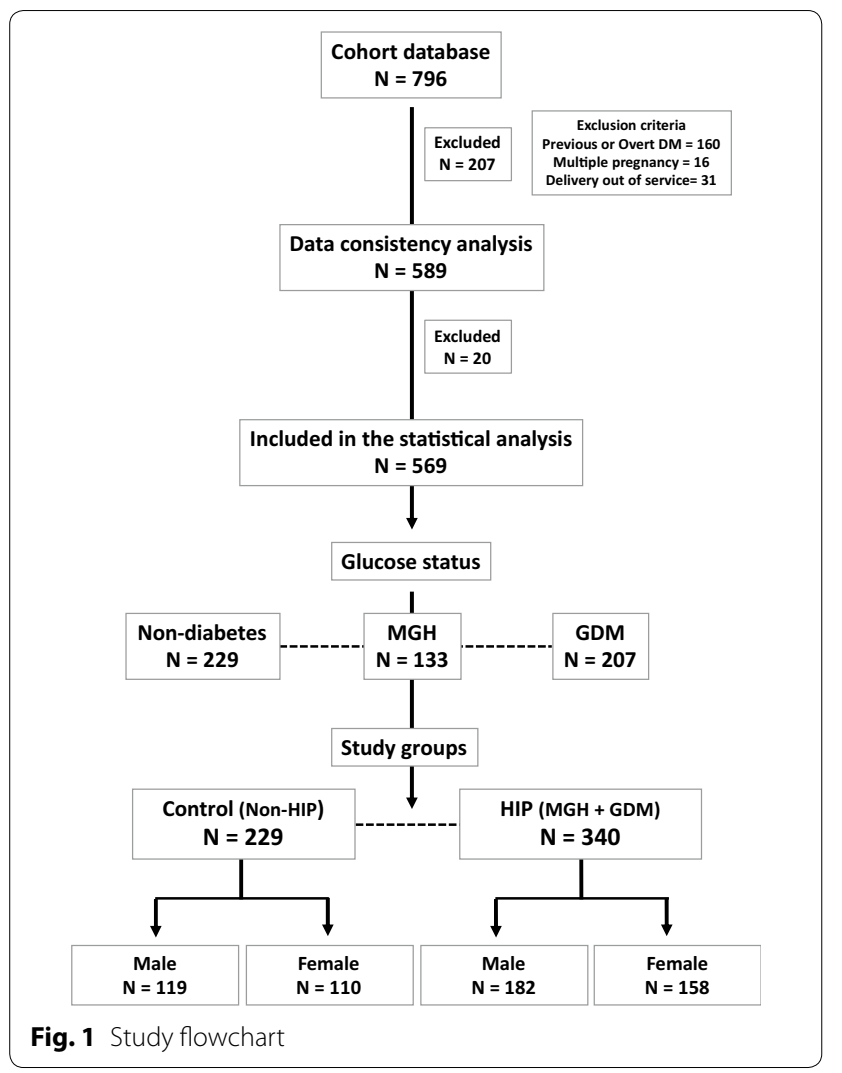

of those women were excluded due to data inconsistency. Thus, 569 pregnant women, with their respective newborns, were classified according to their glucose status-nondiabetes $(\mathrm{N}=229), \mathrm{MGH} \quad(\mathrm{N}=133)$ and GDM $(\mathrm{N}=207)$ - and then distributed into either the HIP group (MGH and GDM; $N=340$ ) or the control group (non-HIP; $\mathrm{N}=229$ ). The prevalence of GDM (39.6 vs $32.2 \% ; p=0.095)$, HIP (GDM+MGH) (58.2 vs $62.3 \% ; p=0.1215$ ), and non-HIP (control) (41.7 vs $37.7 \% ; p=0.3931$ ) was not influenced by diagnostic tests, respectively, $75 \mathrm{~g}$ - or $100 \mathrm{~g}$-OGTT.

Tables 1 and 2 show maternal and pregnancy characteristics and perinatal outcomes according to glucose status. Maternal age $\geq 25$ years, multiparity $(\geq 2)$, nonexercise/sedentarism, and family history of DM differentiated GDM and MGH from the control group but not GDM from the MGH group. The number of prenatal visits $<6$ and the presence of hypertension adequately distinguished GDM from the control group; in the MGH group, these results were intermediate and similar to both the GDM and control groups. Women without a partner were less prevalent in the GDM group, and the prevalence of prepregnancy $\mathrm{BMI} \geq 25 \mathrm{~kg} / \mathrm{m}^{2}$ was proportional to maternal glucose status. Independent of $100 \mathrm{~g}$ or $75 \mathrm{~g}$-OGTT, the mean glucose values of OGTT and of GP were able to differentiate the GDM group from the control group; the MGH group had results that were statistically similar to the control group. Relative to glucose control in pregnancy, cutoff HbA1c levels of $\geq 6.5$ or $6.0 \%$ were both adequate to distinguish hyperglycemia (GDM and $\mathrm{MGH}$ ) from the control group (Table 1).

The frequency of the first $\mathrm{C}$-section was lowest in the GDM group (37.14\%), intermediate in the MGH group (38.20\%) and highest in the control group (57.58\%). The frequency of LGA newborns (GDM $=9.71 \%$, $\mathrm{MGH}=17.19 \%$, control $=6.17 \% ; \mathrm{p}=0.0007)$ and $\mathrm{mac}-$ rosomia $(\mathrm{GDM}=8.21 \%, \mathrm{MGH}=14.39 \%$, control $=5.68 \%$; $\mathrm{p}=0.0171$ ) in the MGH group was higher than that observed in the GDM and control groups, both of which were statistically similar $(\mathrm{MGH}>\mathrm{GDM}=$ control $)$. The prevalence of Z-scores BW/GA > 2.0 was $4.37 \%$ in GDM, statistically similar to that in the MGH group (5.43\%) and higher than that in the control group $(0.44 \%)(p=0.0115$; $\mathrm{GDM}=\mathrm{MGH}<\mathrm{control}$ ). A hematocrit level $>55.0 \%$ was observed in $19.46 \%$ of the GDM group, $11.01 \%$ of the MGH group and $8.96 \%$ of the control group $(p=0.0073$; GDM $>$ MGH = control) (Table 2).

Tables 3 and 4 show maternal and pregnancy characteristics and perinatal outcomes that are associated with HIP, comprising women in the GDM and MGH groups. Among those women, the presence of HIP was associated with age $\geq 25$ years [1.81, 1.44-2.27], number of prenatal visits $<6$ [1.33, 1.11-1.60], multiparity (pregnancy $\geq 2$ ) $[1.82,1.43-2.31]$, nonexercise/sedentarism [0.77, 0.68$0.88]$, not working $[1.17,1.01-1.34]$, family history of DM [1.35, 1.18-1.54], hypertension [1.21, 1.06-1.38], and prepregnancy $\mathrm{BMI} \geq 25 \mathrm{~kg} / \mathrm{m}^{2}[1.82,1.47-2.27]$. As a glucose control marker, an HbA1c level $\geq 6.5$ [1.57, $1.39-1.76]$ or $\geq 6.0 \%$ [1.51, 1.34-1.70] was also associated with HIP (Table 3). The perinatal outcomes associated with HIP were C-section [1.19, 1.02-1.38], LGA newborn [1.30, 1.10-1.54], macrosomia [1.26, 1.05-1.51], BW/GA Z-score $>2.0[1.61,1.40-1.84]$, hematocrit $>65.0 \%[1.70$, $1.58-1.83]$ or $>55.0 \%[1.27,1.07-1.50]$, and sepsis $[1.63$, 1.52-1.75]. Otherwise, the first $\mathrm{C}$-section was less prevalent in the HIP group [0.74, 0.62-0.86] (Table 4).

In Table 5, the logistic regression analysis confirmed that maternal age $\geq 25$ years [1.83, 1.12-2.99], prepregnancy $B M I \geq 25 \mathrm{~kg} / \mathrm{m}^{2}$ [2.88, 1.89-4.39], family history of DM [2.12, 1.42-3.17] and multiparity [2.07, 1.27-3.37] were independent risk factors for HIP. Family history of DM [169, 1.16-2.16] and hypertension [2.00, 1.362.98] were independently associated with C-section. HbA1c $\geq 6.0 \%$ at birth was an independent risk factor for fetal overgrowth, which was indicated by LGA [1.99, 1.05-3.80], macrosomia [2.43, 1.27-4.63], and BW/GA Z-score $>2.0$ [4.17, 1.57-11.10] (Table 5).

Perinatal death occurred in two cases. Briefly, one was an early neonatal death in the nondiabetic group 
Table 1 Maternal and pregnancy characteristics according to glucose status

\begin{tabular}{|c|c|c|c|c|}
\hline Characteristics & $\begin{array}{l}\text { GDM } \\
\mathrm{N}(\%)\end{array}$ & $\begin{array}{l}\text { MGH } \\
\text { N (\%) }\end{array}$ & $\begin{array}{l}\text { ND } \\
\text { N (\%) }\end{array}$ & $p$ value* \\
\hline Age $\geq 25$ years & $181(87.86) a$ & $108(81.20) a$ & $143(62.72) \mathrm{b}$ & $<0.0001$ \\
\hline Prenatal visits $<6$ & $24(13.04) a$ & 10 (9.17)ab & $11(5.26) \mathrm{a}$ & 0.0264 \\
\hline Multiparity ( $\geq 2)$ & $173(86.93) a$ & $110(85.27) a$ & $143(64.71) \mathrm{b}$ & $<0.0001$ \\
\hline Without partner & 14 (7.07)a & $19(14.73) b$ & $36(16.36) b$ & 0.0120 \\
\hline Nonwhite ethnicity & $73(36.87)$ & $47(37.01)$ & $78(35.29)$ & 0.9270 \\
\hline Smoking & $41(19.81)$ & $27(20.30)$ & $34(14.91)$ & 0.2995 \\
\hline Nonexercise/sedentarism & $107(54.04) a$ & $86(67.19) a$ & $160(74.42) \mathrm{b}$ & $<0.0001$ \\
\hline Not working/housewife & $116(58.88)$ & $72(57.14)$ & $106(48.85)$ & 0.0966 \\
\hline Family history of DM (1st degree) & 95 (47.50)a & $54(41.54) a$ & $59(26.94) \mathrm{b}$ & $<0.0001$ \\
\hline Hypertension & 75 (36.23)a & $55(41.67) a b$ & $62(27.43) a$ & 0.0161 \\
\hline Prepregnancy BMI $\geq 25 \mathrm{~kg} / \mathrm{m}^{2}$ & $169(87.56) \mathrm{a}$ & $95(74.80) b$ & $124(56.88) \mathrm{C}$ & $<0.0001$ \\
\hline Excessive weight gain & $77(42.54)$ & $43(37.72)$ & $90(43.48)$ & 0.5885 \\
\hline \multicolumn{5}{|l|}{ OGTT-100 g $(\mathrm{N}=220 ; \mathrm{mg} / \mathrm{dL})^{\mathrm{a}}$} \\
\hline$F P G \geq 95$ & 39 (54.93)a & $6(9.09) \mathrm{b}$ & $0(0.00) \mathrm{b}$ & $<0.0001$ \\
\hline $1 \mathrm{~h} \geq 180$ & $50(70.42) a$ & $3(4.55) b$ & $1(1.20) b$ & $<0.0001$ \\
\hline $2 h \geq 165$ & $52(73.24) a$ & $4(6.06) b$ & $2(2.41) b$ & $<0.0001$ \\
\hline $3 h \geq 140$ & $41(57.75) a$ & $4(6.06) b$ & $0(0.00) b$ & $<0.0001$ \\
\hline \multicolumn{5}{|l|}{ OGTT-75 g $(\mathrm{N}=333 ; \mathrm{mg} / \mathrm{dL})^{\mathrm{b}}$} \\
\hline$F P G \geq 92$ & $77(60.16) a$ & $0(0.00) b$ & $0(0.00) \mathrm{b}$ & $<0.0001$ \\
\hline $1 \mathrm{~h} \geq 180$ & $64(51.20) a$ & $0(0.00) b$ & $0(0.00) b$ & $<0.0001$ \\
\hline $2 h \geq 153$ & $63(50.00) a$ & $0(0.00) b$ & $0(0.00) \mathrm{b}$ & $<0.0001$ \\
\hline GP mean $\geq 120$ mg/dL (at diagnosis) & 14 (6.97)a & $2(1.54) b$ & $1(0.44) b$ & 0.0003 \\
\hline $\mathrm{HbA} 1 \mathrm{c} \geq 6.5 \%$ (at birth) & $21(10.40) a$ & $7(5.51) a$ & $2(0.97) b$ & 0.0002 \\
\hline $\mathrm{HbA} 1 \mathrm{c} \geq 6.0 \%$ (at birth) & $57(28.22) \mathrm{a}$ & $27(21.26) \mathrm{a}$ & $15(7.28) b$ & $<0.0001$ \\
\hline
\end{tabular}

GDM gestational diabetes mellitus, $M G H$ mild gestational hyperglycemia, $N D$ nondiabetes, $D M$ diabetes mellitus, $B M I$ body mass index, OGTT oral glucose tolerance test, $F P G$ fasting plasma glucose, $1 \mathrm{~h}$ 1-h postload, $2 \mathrm{~h}$ 2-h postload, $3 \mathrm{~h}$ 3-h postload, GP glucose profile, HbA1c glycate hemoglobin

* Chi squared or Fisher's exact tests; for each specific variable, values followed by the same letter (a,b or $c)$ are not significantly different ( $p \geq 0.05)$; significant values were highlighted in italic

${ }^{\mathrm{a}}$ Missed $=6 ;{ }^{\mathrm{b}}$ Missed $=10$

that occurred after term vaginal birth (Apgar 1st and 5th $\min =$ zero and Apgar 10th $\min =2$ ); the death was associated with maternal obesity and due to intrapartum hypoxia. The cause of the other perinatal death was unknown; the mother was in the MGH group and was severely obese; the newborn was AGA at term; the death also occurred after vaginal birth.

\section{Discussion}

\section{Maternal characteristics and perinatal outcomes} among different glucose statuses

The results of 569 pregnant women included in a Brazilian cohort of a public referral center showed similarities and differences in maternal and pregnancy characteristics dependent on glucose status. Such differences should be understood and discussed in light of diagnostic criteria and risk factors.

In our cohort, the $100 \mathrm{~g}$ - or $75 \mathrm{~g}$-OGTT diagnostic tests were able to distinguish GDM, but not MGH, from control cases. The mean GP was also not an adequate test to identify either GDM or MGH. However, in a similar population, $\mathrm{FPG} \geq 90 \mathrm{mg} / \mathrm{dL}$ and/or any postprandial level $\geq 130 \mathrm{mg} / \mathrm{dL}$ as measured by the GP test combined with normal 75 g-OGTT was able to identify MGH pregnant women (17.3\%) [11]. Thus, our data reinforce previous considerations about the impact of the diagnostic protocol on the prevalence of hyperglycemia in pregnancy [11]. Besides, point out that the ideal diagnostic tests, and their respective cutoff points, remain undetermined for identifying women who would benefit from strict glucose control [26, 27].

As expected, the elevated HbA1c levels in late pregnancy differentiated both GDM and MGH from controls and can be used to assess the quality of glucose control in pregnancies complicated by hyperglycemia $[20,21]$. According to recent studies, HbA1c values cannot replace OGTTs for the diagnosis of GDM, but it might be a useful tool to reduce the number of 
Table 2 Perinatal outcomes according to glucose status

\begin{tabular}{|c|c|c|c|c|}
\hline Perinatal outcomes & $\begin{array}{l}\text { GDM } \\
\text { N (\%) }\end{array}$ & $\begin{array}{l}\text { MGH } \\
\text { N (\%) }\end{array}$ & $\begin{array}{l}\text { ND } \\
\text { N (\%) }\end{array}$ & $p$-value* \\
\hline Male & $107(51.69)$ & $75(56.39)$ & $119(51.97)$ & 0.6530 \\
\hline C-section & $140(67.63)$ & 89 (66.92) & $132(57.64)$ & 0.0614 \\
\hline First C-section & $52(37.14) a$ & $34(38.20) b$ & $76(57.58) c$ & 0.0014 \\
\hline $\mathrm{GA}<37$ weeks & $20(9.66)$ & $5(3.76)$ & $14(6.11)$ & 0.0931 \\
\hline $\begin{array}{l}\text { Apgar score 5th min } \\
<7\end{array}$ & $7(3.38)$ & $3(2.27)$ & $9(4.04)$ & 0.6740 \\
\hline $\begin{array}{l}\text { Apgar score 10th } \\
\min <7\end{array}$ & $1(0.48)$ & $0(0.00)$ & $1(0.45)$ & 0.7352 \\
\hline Birthweight (g)/GA & & & & 0.0007 \\
\hline SGA & $12(5.83)$ & $13(10.16)$ & $33(14.54)$ & \\
\hline AGA & $174(84.47)$ & $93(72.66)$ & $180(79.30)$ & \\
\hline LGA & 20 (9.71)a & $22(17.19) b$ & $14(6.17) a$ & \\
\hline Macrosomia & $17(8.21) a$ & $19(14.39) \mathrm{b}$ & 13 (5.68)a & 0.0171 \\
\hline Cephal/Abdom < 1.0 & $5(2.45)$ & $4(3.13)$ & $7(3.10)$ & 0.9047 \\
\hline Ponderal index $\geq 2.98$ & $62(30.10)$ & $50(38.76)$ & $60(26.55)$ & 0.0548 \\
\hline BW/GA Z-score $>2.0$ & $9(4.37) \mathrm{a}$ & $7(5.43) a$ & $1(0.44) b$ & 0.0115 \\
\hline Placental index $>0.21$ & $38(19.29)$ & $18(14.63)$ & $32(15.61)$ & 0.4733 \\
\hline Malformation & $5(2.53)$ & $5(3.97)$ & $6(2.84)$ & 0.7488 \\
\hline \multicolumn{5}{|l|}{ Umbilical cord blood } \\
\hline Hematocrit >65.0\% & $4(2.16)$ & $3(2.75)$ & $0(0.00)$ & 0.0810 \\
\hline Hematocrit > 55.0\% & 36 (19.46)a & $12(11.01) b$ & $18(8.96) b$ & 0.0073 \\
\hline Bilirubin $>4.0 \mathrm{mg} / \mathrm{dL}$ & $8(4.21)$ & $3(2.61)$ & $7(3.37)$ & 0.7542 \\
\hline Resuscitation at birth & $39(18.93)$ & $21(16.03)$ & $38(16.74)$ & 0.7496 \\
\hline Respiratory distress ${ }^{a}$ & $15(7.69)$ & $9(7.44)$ & $13(6.53)$ & 0.8986 \\
\hline Phototherapy & $54(27.14)$ & $30(24.39)$ & $52(25.49)$ & 0.8513 \\
\hline Sepsis & $1(0.51)$ & $0(0.00)$ & $0(0.00)$ & 0.4395 \\
\hline $\mathrm{NICU}$ & $6(2.97)$ & $0(0.00)$ & $7(3.23)$ & 0.1330 \\
\hline Perinatal death & $0(0.00)$ & $1(0.82)$ & $1(0.51)$ & 0.4908 \\
\hline Hospital stay $\geq 4$ days & $55(27.92)$ & $25(20.83)$ & $54(25.23)$ & 0.3708 \\
\hline Any $\mathrm{APO}^{\mathrm{b}}$ & $62(29.9)$ & $50(37.6)$ & $60(26.2)$ & 0.07465 \\
\hline
\end{tabular}

GDM gestational diabetes mellitus, $M G H$ mild gestational hyperglycemia, $N D$ nondiabetes, $G A$ gestational age, $S G A$ small for gestational age, $A G A$ adequate for gestational age, $L G A$ large for gestational age, Cephal/Abdom cephalic/ abdominal perimeter ratio, $B W$ birthweight, NICU neonatal intensive care unit

a Respiratory distress-respiratory distress syndrome or meconium aspiration syndrome or persistent pulmonary hypertension or transient tachypnoea of the newborn

b Any adverse perinatal outcome (APO) —any of the following: preterm delivery, LGA, macrosomia, ponderal index $\geq 2.98$, Apgar 5 th $\min <7$, malformation, hospital stay $\geq 4$ days or perinatal death [fetal OR neonatal until the 28th day] * Chi squared or Fisher's exact tests; for each specific variable, values followed by the same letter $(a, b$ or $c)$ are not significantly different $(p \geq 0.05)$; significant values are highlighted in italic

OGTTs, associated costs and the level of inconvenience to women $[28,29]$.

Both GDM and MGH pregnant women were older, multiparous, were more likely to have a family history of DM and were more adherent to the exercise practice. For this population, maternal age $\geq 25 \mathrm{~kg} / \mathrm{m}^{2}$, parity $\geq 2$, family history of DM and regular exercise were characteristics common to both MGH and GDM and represented a potential risk for hyperglycemia in pregnancy. Conversely, GDM was less frequent in pregnant women without partners.

Although controversial, maternal age $\geq 25$ years, $\mathrm{BMI} \geq 25$ or $30 \mathrm{~kg} / \mathrm{m}^{2}$, previous macrosomia and GDM, and a family history of DM were related to hyperglycemia in pregnancy $[13,17]$ and reinforce our results. However, it is surprising that regular exercise represents a risk for hyperglycemia in our cohort. This result may be explained by the higher prevalence of $\mathrm{BMI} \geq 25 \mathrm{~kg} / \mathrm{m}^{2}$ in the GDM and MGH groups and by our clinical protocol, which recommends exercise practice for all overweight or obese pregnant women, even before maternal hyperglycemia screening.

Regardless of the strict glucose control in the GDM and MGH groups [20,21], adverse perinatal outcomes were more frequent in the MGH status group. The prevalences of first C-section, LGA, and macrosomia, which are direct or indirect markers of fetal overgrowth, were higher in the MGH group than in the control or GDM groups. These results point out two important issues. First, pregnant women in the GDM group were subjected to adequate glycemic control and obtained similar perinatal results to the control group (without hyperglycemia), and this is a good and expected result. Second, pregnant women with MGH had the worst perinatal results, which could not be expected.

Compared to the GDM group, the MGH group was less likely to have pregestational $\mathrm{BMI} \geq 25 \mathrm{~kg} / \mathrm{m}^{2}$, had a similar prevalence of excessive weight gain during pregnancy, and had adequate levels of HbA1c at birth, which could not prove the cause-effect relationship between MGH and fetal overgrowth. However, our pioneering study showed that the glucose profile showed a greater sensitivity and positive predictive value (PPV) for predicting fetal macrosomia, independent of the normal OGTT [9]. These results highlight the validity of the search for and the need for glucose control in patients with MGH [8-11, $24,30,31]$.

\section{The independent risk factors for HIP}

To assess the risk factors for HIP, GDM and MGH were approached as a unique group, named hyperglycemia in pregnancy (HIP). After bivariate analysis, maternal age $\geq 25$ years, prenatal visits $<6$, multiparity, not working, family history of DM, hypertension, prepregnancy $\mathrm{BMI} \geq 25 \mathrm{~kg} / \mathrm{m}^{2}$, and elevated HbA1c levels at birth were associated with HIP; women who did not comply with the exercise recommendation were less prevalent in the HIP group. The logistic regression analysis confirmed that age $\geq 25$ years, prepregnancy $B M I \geq 25 \mathrm{~kg} / \mathrm{m}^{2}$, family 
Table 3 Maternal and pregnancy characteristics according to the study groups, with respective unadjusted risk ratios (RRs) and 95\% confidence intervals (Cls)

\begin{tabular}{|c|c|c|c|c|}
\hline Characteristics & $\begin{array}{l}\text { HIP } \\
\text { N (\%) }\end{array}$ & $\begin{array}{l}\text { Control } \\
\mathrm{N}(\%)\end{array}$ & $\begin{array}{l}\text { RR } \\
{[95 \% \mathrm{Cl}]^{*}}\end{array}$ & Missing \\
\hline Age $\geq 25$ years & $289(85.25)$ & $143(62.72)$ & $1.81[1.44-2.27]$ & 2 \\
\hline Prenatal visits $<6$ & $34(11.60)$ & $11(5.26)$ & $1.33[1.11-1.60]$ & 67 \\
\hline Multiparity $(\geq 2)$ & $283(86.28)$ & $143(64.71)$ & $1.82[1.43-2.31]$ & 20 \\
\hline Without partner & $33(10.09)$ & $36(16.36)$ & $0.78[0.60-1.00]$ & 22 \\
\hline Nonwhite ethnicity & $120(36.92)$ & $78(35.29)$ & $1.03[0.89-1.19]$ & 23 \\
\hline Smoking & $68(20.00)$ & $34(14.91)$ & $1.14[0.98-1.34]$ & 1 \\
\hline Nonexercise/sedentarism & $193(59.20)$ & $160(74.42)$ & $0.77[0.68-0.88]$ & 28 \\
\hline Not working/housewife & $188(58.20)$ & $106(48.85)$ & $1.17[1.01-1.34]$ & 29 \\
\hline Family history of DM (1st degree) & $149(45.15)$ & $59(26.94)$ & $1.35[1.18-1.54]$ & 20 \\
\hline Hypertension & $130(38.35)$ & $(27.43)$ & $1.21[1.06-1.38]$ & 4 \\
\hline Prepregnancy BMI $\geq 25 \mathrm{~kg} / \mathrm{m}^{2}$ & $264(82.50)$ & $124(56.88)$ & $1.82[1.47-2.27]$ & 31 \\
\hline Excessive weight gain & $120(40.68)$ & $90(43.48)$ & $0.95[0.82-1.11]$ & 67 \\
\hline \multicolumn{5}{|l|}{ OGTT-100 g (N=220; mg/dL) } \\
\hline$F P G \geq 95$ & $45(32.85)$ & $0(0.00)$ & $1.90[1.65-2.19]$ & - \\
\hline $1 \mathrm{~h} \geq 180$ & $53(38.69)$ & $1(1.20)$ & $1.94[1.66-2.26]$ & - \\
\hline $2 \mathrm{~h} \geq 165$ & $56(40.88)$ & $2(2.41)$ & $1.93[1.64-2.17]$ & - \\
\hline $3 h \geq 140$ & $45(32.85)$ & $0(0.00)$ & $1.90[1.65-2.19]$ & - \\
\hline \multicolumn{5}{|l|}{ OGTT-75 g (N=333; mg/dL) } \\
\hline$F P G \geq 92$ & $77(40.53)$ & $0(0.00)$ & $2.23[1.94-2.56]$ & 4 \\
\hline $1 \mathrm{~h} \geq 180$ & $64(34.22)$ & $0(0.00)$ & $2.13[1.87-2.42]$ & 7 \\
\hline $2 h \geq 153$ & $63(33.51)$ & $0(0.00)$ & $2.11[1.86-2.40]$ & 6 \\
\hline $\mathrm{GP}$ mean $\geq 120 \mathrm{mg} / \mathrm{dL}$ (at diagnosis) & $16(4.83)$ & $1(0.44)$ & $1.61[1.40-1.85]$ & 13 \\
\hline $\mathrm{HbA} 1 \mathrm{c} \geq 6.5 \%$ (at birth) & $28(8.51)$ & $2(0.97)$ & $1.57[1.39-1.76]$ & 34 \\
\hline $\mathrm{HbA} 1 \mathrm{c} \geq 6.0 \%$ (at birth) & $34(25.53)$ & $15(7.28)$ & $1.51[1.34-1.70]$ & 34 \\
\hline
\end{tabular}

HIP hyperglycemia in pregnancy (GDM + MGH), DM diabetes mellitus, BMI body mass index; OGTT oral glucose tolerance test, $F P G$ fasting plasma glucose, $1 \mathrm{~h}$ : $1-\mathrm{h}$ postload, $2 \mathrm{~h}$ 2-h postload, $3 \mathrm{~h}$ : 3-h postload, GP glucose profile, HbA1c glycate hemoglobin

* Significant values of RR $[95 \% \mathrm{Cl}]$ are highlighted in italic

history of DM and multiparity were independent risk factors for HIP. Interestingly, as shown in Table 1, the proportion of these independent risks was statically similar between the GDM and MGH groups. This finding reinforces the validity of evaluating GDM and MGH as a unique hyperglycemic condition.

For clinical practice, our results reinforce the use selective screening, in which only multiparous women with a family history of DM, aged $\geq 25$ years, and $B M I \geq 25 \mathrm{~kg} /$ $\mathrm{m}^{2}$ would be directed to diagnostic tests (OGTT and GP). There is still debate in the literature about this topic [23-25]. While some authors indicate that a simple offer of an OGTT to women aged $\geq 25$ years old and/or with a $\mathrm{BMI} \geq 25 \mathrm{~kg} / \mathrm{m}^{2}$ is as effective as more complex risk prediction models [7, 17], others concluded that risk-based screening may miss up to $30 \%$ of women with GDM because not all women have identifiable risk factors [13, $14,16,17,26,27,32-34]$. Our results may contribute to this issue, especially in populations and referral centers with similar characteristics.
Overweight and obesity is a real worldwide public health problem, as observed in our referral center. Previous studies have already identified the association between maternal adiposity and hyperglycemia, pointing out maternal age as the modulating factor in both multiparous [24, 35-39] and nulliparous women [40-42]. Although not fully defined, the current literature supports our findings.

\section{The independent risk factors for HIP-related adverse outcomes}

In the present study, perinatal outcomes were worse in pregnancies complicated by HIP, independent of GDM or MGH. C-section, LGA and macrosomic newborns, Z-score BW/GA $>2.0$, hematocrit levels $>65$ or $55 \%$, and sepsis were statistically associated with the HIP group. Conversely, the first C-section was more commonly associated with the control group, and fetal sex was not associated with HIP. 
Table 4 Perinatal outcomes according to the study groups, with respective unadjusted risk ratios (RRs) and 95\% confidence intervals (Cls)

\begin{tabular}{|c|c|c|c|c|}
\hline $\begin{array}{l}\text { Perinatal } \\
\text { outcomes }\end{array}$ & $\begin{array}{l}\text { HIP } \\
\text { N (\%) }\end{array}$ & $\begin{array}{l}\text { Control } \\
\text { N (\%) }\end{array}$ & $\begin{array}{l}\text { RR } \\
{[95 \% \mathrm{Cl}]}\end{array}$ & Missing \\
\hline Male & $182(53.53)$ & $119(51.97)$ & $1.03[0.90-1.17]$ & - \\
\hline C-section & $229(67.35)$ & $132(57.64$ & $1.19[1.02-1.38]$ & - \\
\hline First C-section & $86(38.91)$ & $76(58.91)$ & $0.74[0.62-0.86]$ & - \\
\hline $\mathrm{GA}<37$ weeks & $25(7.35)$ & $14(6.11)$ & 1.08 [0.84-1.38] & - \\
\hline $\begin{array}{l}\text { Apgar score 5th } \\
\min <7\end{array}$ & $10(2.95)$ & $9(4.04)$ & $0.89[0.56-1.34]$ & 7 \\
\hline $\begin{array}{l}\text { Apgar score 10th } \\
\min <7\end{array}$ & $1(0.30)$ & $1(0.45)$ & $0.83[0.21-3.32]$ & 8 \\
\hline LGA & $42(12.57)$ & $14(6.17)$ & $1.30[1.10-1.54]$ & 8 \\
\hline Macrosomia & $36(10.62)$ & $13(5.68)$ & $1.26[1.05-1.51]$ & 1 \\
\hline $\begin{array}{l}\text { Cephal/ } \\
\text { Abdom }<1.0\end{array}$ & $9(2.71)$ & $7(3.10)$ & $0.94[0.61-1.46]$ & 11 \\
\hline $\begin{array}{l}\text { Ponderal } \\
\quad \text { index } \geq 2.98\end{array}$ & $112(33.43)$ & $60(26.55)$ & 1.14 [0.99-1.31] & 8 \\
\hline $\begin{array}{l}\text { BW/GA } \\
\text { Z-score }>2.0\end{array}$ & $16(4.78)$ & $1(0.44)$ & $1.61[1.40-1.84]$ & 8 \\
\hline $\begin{array}{l}\text { Placental } \\
\quad \text { index }>0.21\end{array}$ & $56(17.50)$ & $32(15.61)$ & $1.05[0.88-1.26]$ & 44 \\
\hline Malformation & $10(3.09)$ & $6(2.84)$ & $1.03[0.70-1.52]$ & 34 \\
\hline Hematocrit $>65.0 \%$ & $7(2.38)$ & $0(0.00)$ & $1.70[1.58-1.83]$ & 74 \\
\hline Hematocrit $>55.0 \%$ & $48(16.33)$ & $18(8.96)$ & $1.27[1.07-1.50]$ & 74 \\
\hline $\begin{array}{l}\text { Bilirubin > } 4.0 \text { mg/ } \\
\quad \mathrm{dL}\end{array}$ & $11(3.61)$ & $7(3.37)$ & $1.03[0.71-1.50]$ & 56 \\
\hline $\begin{array}{l}\text { Resuscitation at } \\
\text { birth }\end{array}$ & $60(17.80)$ & $38(16.74)$ & $1.03[0.87-1.23]$ & 5 \\
\hline $\begin{array}{l}\text { Respiratory } \\
\text { distress }^{\mathrm{a}}\end{array}$ & $24(7.59)$ & $13(6.53)$ & 1.06 [0.83-1.36] & 54 \\
\hline Phototherapy & $84(26.09)$ & $52(25.49)$ & $1.01[0.87-1.18]$ & 43 \\
\hline Sepsis & $1(0.32)$ & $0(0.00)$ & $1.63[1.52-1.75]$ & 54 \\
\hline $\mathrm{NICU}$ & $6(1.83)$ & $7(3.2)$ & $0.76[0.42-1.38]$ & 24 \\
\hline Perinatal death & $1(0.31)$ & $1(0.51)$ & $0.81[0.20-3.25]$ & 53 \\
\hline $\begin{array}{l}\text { Hospital } \\
\text { stay } \geq 4 \text { days }\end{array}$ & $80(25.24)$ & $54(25.23)$ & $1.00[0.85-1.17]$ & 38 \\
\hline Any $\mathrm{APO}^{\mathrm{b}}$ & $112(32.94)$ & $60(26.20)$ & $1.13[1.00-1.30]$ & - \\
\hline
\end{tabular}

HIP hyperglycemia in pregnancy (GDM $+M G H)$, GA gestational age, SGA small for gestational age, $A G A$ adequate for gestational age, $L G A$ large for gestational age, Cephal/Abdom cephalic/abdominal ratio, BW birthweight, NICU neonatal intensive care unit

a Respiratory distress-respiratory distress syndrome or meconium aspiration syndrome or persistent pulmonary hypertension or transient tachypnoea of the newborn

b Any APO-any of the following: preterm delivery, LGA, macrosomia, ponderal index $\geq 2.98$, Apgar 5 th $\min <7$, malformation, hospital stay $\geq 4$ days or perinatal death [fetal OR neonatal until the 28th day]

Specifically, for GDM, fetal and neonatal complications include C-section, macrosomia, shoulder dystocia, birth trauma, neonatal hypoglycemia and hyperbilirubinemia, and respiratory distress syndrome (RDS) $[26,43,44]$. In addition, milder forms, which do
Table 5 Results of the logistic regression analysisadjusted risk $\left(\mathbf{R R}_{\mathrm{adj}}\right)$ and $\mathbf{9 5 \%}$ confidence intervals $(\mathrm{Cls})$ of maternal and pregnancy characteristics (exposure) for HIP and perinatal outcomes (response)

\begin{tabular}{llll}
\hline Exposure & Outcome & RR $_{\text {adj }}$ & $\mathbf{9 5 \%} \mathbf{C l}$ \\
\hline Age $\geq 25$ years & HIP & 1.83 & $1.12-2.99$ \\
Prepregnancy BMI $\geq 25 \mathrm{~kg} / \mathrm{m}^{2}$ & & 2.88 & $1.89-4.39$ \\
$\begin{array}{l}\text { Family history of DM (1st } \\
\quad \text { degree) }\end{array}$ & & 2.12 & $1.42-3.17$ \\
Multiparity $(\geq 2)$ & & \\
Family history of DM (1st & C-section & 1.07 & $1.27-3.37$ \\
$\quad$ degree) & & $1.16-2.16$ \\
Hypertension & & \\
Prepregnancy BMI $\geq 25 \mathrm{~kg} / \mathrm{m}^{2}$ & 1st C-section & 0.45 & $0.27-0.57$ \\
HbA1c $>6.0 \%$ & LGA & 1.99 & $1.05-3.80$ \\
& Macrosomia & 2.43 & $1.27-4.63$ \\
& BW/GA Z-score $>2.0$ & 4.17 & $1.57-11.10$
\end{tabular}

Variables tested in the forward model: exposure $=$ all significant results in Table 3 (maternal and pregnancy characteristics); outcomes = HIP (hyperglycemia in pregnancy) and all significant results in Table 4 (perinatal outcomes)

HIP hyperglycemia in pregnancy (GDM + MGH), GA gestational age, LGA large for gestational age, $B W$ birthweight, $B M I$ body mass index, $D M$ diabetes mellitus, $H b A 1 c$ glycate hemoglobin

not fully meet GDM diagnostic criteria, were associated with hyperglycemia and adverse outcomes, including LGA, macrosomia, first C-section, and hospital length above 3 days [8-11]. Regardless of the inconsistency in perinatal outcomes evaluated in reviews or even in randomized trials [45], the literature supports our findings.

Some authors have reported increased rates of C-section and differences in outcomes relative to fetal sex, with a worse outcome for male newborns in GDM pregnancies [46, 47]. Our results are not consistent with these previous findings, probably due to the specificity of the population. In our cohort, the rates of first $\mathrm{C}$-section were higher in the control group, thus potentially explaining the recurrence in this group and the lower rates in the HIP group. Relative to the influence of sex, the proportions of male and female newborns were equivalent, which may have contributed to the similarity in HIP outcomes.

The logistic regression analysis defined the independent risk factors for HIP adverse outcome. Family history of DM and hypertensive disorders were independently associated with $\mathrm{C}$-section, and an HbAlc level $>6.0 \%$ was an independent risk factor for LGA, macrosomia, and $\mathrm{Z}$-score $\mathrm{BW} / \mathrm{GA}>2.0$. In contrast, prepregnancy $B M I \geq 25 \mathrm{~kg} / \mathrm{m}^{2}$ was a protective factor for the first C-section.

Although the adverse outcomes evaluated in this study were associated with HIP, the logistic regression analysis did not identify the diagnostic tests and 
their cutoff points as independent risk factors. We also assessed maternal and pregnancy characteristics among DMG, MGH, and nondiabetic status. It is possible that the inadequacy of the tests and the fact that their cutoff points have yet to be defined could explain this issue $[26,27,44]$. HbA1c levels $>6.0 \%$ at late gestation were independently associated with fetal overgrowth as indicated by LGA, macrosomia, and Z-score $\mathrm{BW} / \mathrm{GA}>2.0$. This result highlights the validity of strict glucose control $[20,21]$. The HbA1c levels recommended for achieving glucose control during pregnancy are 6.0 to $6.5 \%$ [23]. According to our results, an $\mathrm{HbA} 1 \mathrm{c}$ of $6.5 \%$ may be inadequate to prevent large or macrosomic newborns, and this issue must be confirmed in future studies.

In our study, a prepregnancy $B M I \geq 25 \mathrm{~kg} / \mathrm{m}^{2}$ was confirmed as a protective factor against first C-section. As previously commented, this result may be population dependent. The higher first $\mathrm{C}$-section rate in the control group and the management protocol of all overweight or obese pregnant women with nutritional counseling and exercise to prevent HIP could explain this question. Although not expected, this result highlights the potential benefit of lifestyle changes to prevent maternal hyperglycemia and its adverse outcomes $[23,36,38]$.

Finally, our results support the association between maternal adiposity and hyperglycemia, and the maternal age as the modulating factor [24, 35-42]. Overweight and obesity appear to be the main drivers in HIP development. Thus, efforts must be made to improve optimal lifestyle management in childhood, adolescence, and adult life, particularly in the pre- and pregnancy phases, to curb the current epidemic of obesity due to its adverse repercussions for both mothers and newborns.

\section{Strength and limitations}

Our study has some limitations. The sample size was calculated based on the frequency of LGA newborns and may compromise the statistical power for other perinatal outcomes evaluated. In this context, the specific characteristics of our referral center may make it difficult to reproduce the results. The strength of this study is that it includes different glucose statuses identified by $100 \mathrm{~g}$ - or $75 \mathrm{~g}$-OGTT and glucose profiles, includes a sufficient sample size from a unique referral center, and uses well-defined diagnostic and management protocols, thus strengthen the consistency and quality of the data. In addition, our results raised important issues: (i) the validity of glucose control in MGH status and the need to detect and treat MGH in pregnant women; (ii) the possible inadequacy of the $\mathrm{HbA} 1 \mathrm{c}$ cutoff at $6.5 \%$ to detect large or macrosomic newborns; and (iii) the potential benefit of lifestyle changes, with adequate diet and regular exercise, in the prevention of maternal hyperglycemia and its adverse outcomes. These issues lead to several possibilities for future research.

\section{Conclusions}

The results of a Brazilian cohort referral center indicated that the intensity of maternal hyperglycemia affects pregnancy outcomes. MGH presents adverse pregnancy outcomes similar to those observed in the GDM group but distinct from the control (no diabetes) group. In our cohort, age $\geq 25$ years, prepregnancy $B M I \geq 25 \mathrm{~kg} / \mathrm{m}^{2}$, family history of DM, and multiparity were independent risk factors for HIP, supporting the selective screening for this condition.

Our results should be validated in populations with the same characteristics in Brazil or other low- or middleincome countries. Such results would provide evidence to determine the best approach for HIP diagnosis.

\section{Acknowledgements \\ The authors are thankful to the Research Support Center (GAP) of Botucatu Medical School, Unesp, for technical support.}

\section{Authors' contributions}

$B N$, IMPC, and JGC designed and performed the analysis from the original cohort. JMV, RAC, CGM, and MVCR contributed to data analysis and interpretation. JEC was responsible for the statistical analysis. BN and IMPC wrote and JGC reviewed the initial version of the manuscript. All authors read, reviewed this final version for publication. All authors read and approved the final manuscript.

\section{Funding}

Conselho Nacional de Desenvolvimento Científico e Tecnológico (PQ-CNPq 304771/2015-5)

\section{Availability of data and materials}

All authors declare that data and any supporting material regarding this manuscript are available and can be requested at any time.

\section{Ethics approval and consent to participate}

The cohort study proposal has been reviewed and approved by the Institutional Review Board of the Botucatu Medical School/Unesp (Protocol $\# 1$ 14033/2015). All patients included in the study provided written consent to participate.

\section{Competing interests}

The authors declare that partial data from this study were previously published [11].

\section{Author details \\ ${ }^{1}$ Graduate Program of Gynecology, Obstetrics and Mastology, Botucatu Medi- cal School, Unesp, Botucatu, SP, Brazil. ${ }^{2}$ Department of Obstetrics and Gyne- cology, Botucatu Medical School, Unesp, Botucatu, SP, Brazil. ${ }^{3}$ Department of Biostatistics, Botucatu Bioscience Institute (BBI), Unesp, Botucatu, SP, Brazil. ${ }^{4}$ Department of Obstetrics and Gynecology, University of Campinas (UNI- (AMP), School of Medical Sciences, Campinas, SP, Brazil.}

Received: 27 February 2020 Accepted: 26 May 2020

Published online: 06 June 2020 


\section{References}

1. International Association of Diabetes and Pregnancy Study Groups. Recommendations on the diagnosis and classification of hyperglycemia in pregnancy. Diabetes Care. 2010;33(3):676-82.

2. World Health Organization. Diagnostic criteria and classification of hyperglycaemia first detected in pregnancy. Geneva: WHO; 2013. http://apps. who. int/iris/bitstream/10665/85975/1/WHO_NMH_MND_13.2_eng. pdf. Accessed 23 Nov 2018.

3. Hod M, Kapur A, Sacks DA, Hadar E, Agarwal M, Di Renzo GC, Cabero Roura L, McIntyre HD, Morris JL, Divakar H. The International Federation of Gynecology and Obstetrics (FIGO) Initiative on gestational diabetes mellitus: a pragmatic guide for diagnosis, management, and care. Int Gynaecol Obstet. 2015;131(Suppl 3):173-211.

4. O'Sullivan EP, Avalos G, O'Reilly M, Dennedy MC, Gaffney G, Dunne F, Atlantic DIP Collaborators. Atlantic DIP: the prevalence and consequences of gestational diabetes in Ireland. Ir Med J. 2012;105(5 Suppl):13-5.

5. Yessoufou A, Moutairou K. Maternal diabetes in pregnancy: early and long-term outcomes on the offspring and the concept of "metabolic memory". Exp Diabetes Res. 2011:2011:1-12.

6. Malcolm J. Through the looking glass: gestational diabetes as a predictor of maternal and offspring long-term health. Diabetes Metab Res Rev. 2012;28(4):307-11.

7. Vrachnis N, Augoulea A, lliodromiti Z, Lambrinoudaki I, Sifakis S, Creatsas G. Previous gestational diabetes mellitus and markers of cardiovascular risk. Int J Endocrinol. 2012;2012:1-6.

8. Rice MM, Landon MB. What we have learned about treating mild gestational diabetes mellitus. Semin Perinatol. 2016;40(5):298-302.

9. Rudge MV, Peraçoli JC, Berezowski AT, Calderon IM, Brasil MA. The oral glucose tolerance test is a poor predictor of hyperglycemia during pregnancy. Braz J Med Biol Res. 1990;23(11):1079-89.

10. Rudge MVC, Calderon IMP, Ramos MD, Brasil MAM, Rugolo LMSS, Bossolan G, et al. Hiperglicemia materna diária diagnosticada pelo perfil glicêmico: um problema de saúde pública materno e perinatal. Rev Bras Ginecol Obstet. 2005;27(11):691-7.

11. Sirimarco MP, Guerra HM, Lisboa EG, Vernini JM, Cassetari BN, Costa RAA, et al. Diagnostic protocol for gestational diabetes mellitus (GDM) (IADPSG/ADA, 2011): influence on the occurrence of GDM and mild gestational hyperglycemia $(\mathrm{MGH})$ and on the perinatal outcomes. Diabetol Metab Syndr. 2017:9:2 (eCollection)

12. Organização Pan-Americana da Saúde. Ministério da Saúde. Federação Brasileira das Associações de Ginecologia e Obstetrícia. Sociedade Brasileira de Diabetes (Ed.). Rastreamento e diagnóstico de diabetes mellitus gestacional no Brasil [publication on line]. Brasília: OPAS; 2016. 32p. http:// iris.paho.org/xmlui/handle/123456789/34278?show=full. Accessed 23 Nov 2018.

13. Van Leeuwen M, Opmeer BC, Zweers EJ, van Ballegooie E, ter Brugge HG, de Valk HW, et al. Estimating the risk of gestational diabetes mellitus: a clinical prediction model based on patient characteristics and medical history. BJOG. 2010;117(1):69-75.

14. Cosson E, Benbara A, Pharisien I, Nguyen M, Revaux A, Lormeau B, et al. Diagnostic and prognostic performances over 9 years of a selective screening strategy for gestational diabetes mellitus in a cohort of 18,775 subjects. Diabetes Care. 2012;36(3):598-603.

15. Trujillo J, Vigo A, Reichelt A, Duncan BB, Schmidt MI. Fasting plasma glucose to avoid a full OGTT in the diagnosis of gestational diabetes. Diabetes Res Clin Pract. 2016;105(3):322-6.

16. Zhang C, Rawal S, Chong Y. Risk factors for gestational diabetes: is prevention possible? Diabetologia. 2016;59(7):1385-90.

17. Farrar $D$, Simmonds $M$, Bryant $M$, et al. Risk factor screening to identify women requiring oral glucose tolerance testing to diagnose gestational diabetes: a systematic review and meta-analysis and analysis of two pregnancy cohorts. PLOS ONE. 2017;12(4):e0175288.

18. American Diabetes Association. Diagnosis and classification of diabetes mellitus (position statement). Diabetes Care. 2010;33(Suppl 1):S62-9.

19. American Diabetes Association. Diagnosis and classification of diabetes mellitus (position statement). Diabetes Care. 2011;34(Suppl 1):S62-9.

20. Metzger BE, Buchanan TA, Coustan DR, de Leiva A, Dunger DB, Had den DR, Hod M, Kitzmiller JL, Kjos SL, Oats JN, Pettitt DJ, Sacks DA, Zoupas C. Summary and recommendations of the Fifth International
Workshop-Conference on Gestational Diabetes Mellitus. Diabetes Care. 2007;30(Suppl 2):S251-60.

21. American Diabetes Association. Classification and diagnosis of diabetes: standards of medical care in diabetes-2018. Diabetes Care. 2018:41(Suppl 1):S13-27. https://doi.org/10.2337/dc18-S002.

22. Word Health Organization. WHO recommendations on antenatal care for a positive pregnancy experience. Geneva:WHO; 2016. http://apps. who.int/iris/bitstream/handle/10665/250796/9789241549912-eng. pdf;jsessionid=DDABC790D5477B711DAAACA94EB9D41B?seque nce=1. Accessed 23 Nov 2018

23. American Diabetes Association. Management of diabetes in pregnancy: standards of medical care in diabetes - 2018. Diabetes Care. 2018;41(Suppl 1):S137-43. https://doi.org/10.2337/dc18-S013.

24. Vernini JM, Moreli JB, Magalhães CG, Costa RAA, Rudge MVC, Calderon IMP. Maternal and fetal outcomes in pregnancies complicated by overweight and obesity. Reprod Health. 2016;13(1):100. https://doi. org/10.1186/s12978-016-0206-0.

25. Fenton TR, Kim JH. A systematic review and meta-analysis to revise the Fenton growth chart for preterm infants. BMC Pediatr. 2013;13:59.

26. Farrar D, Medley N, Duley L, Lawlor D. Different strategies for diagnosing gestational diabetes to improve maternal and infant health. Cochrane Database Syst Rev. 2015;1:CD007122.

27. Farrar D. Hyperglycemia in pregnancy: prevalence, impact, and management challenges. Int J Women's Health. 2016;8:519-27.

28. Benaiges D, Flores-Le Roux JA, Marcelo I, Mane L, Rodriguez M, Navarro X, Chillaron JJ, Llaurado G, Gortazar L, Pedro-Botet J, et al. Is first-trimester $\mathrm{HbA} 1 \mathrm{c}$ useful in the diagnosis of gestational diabetes? Diabetes Res Clin Pract. 2017;133:85-91.

29. Siricharoenthai P, Phupong V. Diagnostic accuracy of HbA1c in detecting gestational diabetes mellitus. J Matern Fetal Neonatal Med. 2019. https://doi.org/10.1080/14767058.2019.1576169.

30. Landon MB, Mele L, Spong CY, Carpenter MW, Ramin SM, Casey B, et al. Eunice Kennedy Shriver National Institute of Child Health, and Human Development (NICHD) Maternal-Fetal Medicine Units (MFMU) Network. The relationship between maternal glycemia and perinatal outcome. Obstet Gynecol. 2011;117(2):218-24.

31. Landon MB, Rice MM, Varner MW, Casey BM, Reddy UM, Wapner RJ, et al. Eunice Kennedy Shriver National Institute of Child Health and Human Development Maternal-Fetal Medicine Units (MFMU) Network Mild gestational diabetes mellitus and long-term child health. Diabetes Care. 2015;38(3):445-52.

32. Dahanayaka NJ, Agampodi SB, Ranasinghe OR, et al. Inadequacy of the risk factor based approach to detect gestational diabetes mellitus. Ceylon Med J. 2012:57(1):5-9.

33. Avalos GE, Owens LA, Dunne F, Collaborators AD. Applying current screening tools for gestational diabetes mellitus to a European population: is it time for change? Diabetes Care. 2013;36(10):3040-4.

34. Badon SE, Zhu Y, Sridhar SB, et al. a pre-pregnancy biomarker risk score improves prediction of future gestational diabetes. J Endocr Soc. 2018;2(10):1158-69.

35. Sacks DA, Hadden DR, Maresh M, et al. Frequency of gestational diabetes mellitus at collaborating centers based on IADPSG consensus panel-recommended criteria: the Hyperglycemia and Adverse Pregnancy Outcome (HAPO) Study. Diabetes Care. 2012;35:526-8.

36. Dennedy MC, Avalos G, O'Reilly MW, et al. ATLANTIC-DIP: raised Maternal Body Mass Index (BMI) adversely affects maternal and fetal outcomes in glucose-tolerant women according to International Association of Diabetes and Pregnancy Study Groups (IADPSG) criteria. J Clin Endocrinol Metab. 2012;97(4):E608. https://doi.org/10.1210/ jc.2011-2674.

37. Bolognani C, de Sousa Moreira Reis L, de Souza S, et al. Waist circumference in predicting gestational diabetes mellitus. J Matern Fetal Neonatal Med. 2014;27(9):943-8.

38. Shin D, Song WO. Prepregnancy body mass index is an independent risk factor for gestational hypertension, gestational diabetes, preterm labor, and small- and large-for-gestational-age infants. J Matern Fetal Neonatal Med. 2015;28:1679-86.

39. Collier A, Abraham EC, Armstrong J, et al. Reported prevalence of gestational diabetes in Scotland: the relationship with obesity, age, socioeconomic status, smoking and macrossomia, and how many are we missing? J Diabetes Investig. 2017;8:161-7. 
40. Liu L, Hong Z, Zhang L. Associations of prepregnancy body mass index and gestational weight gain with pregnancy outcomes in nulliparous women delivering single live babies. Sci Rep. 2015;5:12863.

41. Ben-David A, Glasser S, Schiff E, et al. Pregnancy and birth outcomes among primipara at very advanced maternal age: at what price? Matern Child Health J. 2016;20:833-42.

42. Laine MK, Kautiainen $\mathrm{H}$, Gissler M, et al. Gestational diabetes in primiparous women -impact of age and adiposity: a register-based cohort study. Acta Obstet Gynecol Scand. 2018:97:187-94.

43. American College of Obstetrics and Gynecology (ACOG). Committee on practice bulletins_-obstetrics. ACOG Practice bulletin no. 190: Gestational Diabetes Mellitus. Obstet Gynecol 2018;131(2):e49-e64.

44. Farrar D, Simmonds M, Bryant M, Sheldon TA, Tuffnell D, Golder S, Dunne F, Lawlor DA. Hyperglycaemia and risk of adverse perinatal outcomes: systematic review and meta-analysis. BMJ. 2016;354:14694.
45. Bain E, Middleton P, Crowther CA. Progressing towards standard outcomes in gestational diabetes Cochrane reviews and randomized trials. Aust N Z J Obstet Gynaecol. 2016;56(1):113-6.

46. Tundidor D, García-Patterson A, María MA, Ubeda J, Ginovart G, Adelantado JM, de Leiva A, Corcoy R. Perinatal maternal and neonatal outcomes in women with gestational diabetes mellitus according to fetal sex. Gend Med. 2012;9(6):411-7.

47. Regnault N, Gillman MW, Rifas-Shiman SL, Eggleston E, Oken E. Sexspecific associations of gestational glucose tolerance with childhood body composition. Diabetes Care. 2013;36(10):3045-53.

\section{Publisher's Note}

Springer Nature remains neutral with regard to jurisdictional claims in published maps and institutional affiliations.
Ready to submit your research? Choose BMC and benefit from:

- fast, convenient online submission

- thorough peer review by experienced researchers in your field

- rapid publication on acceptance

- support for research data, including large and complex data types

- gold Open Access which fosters wider collaboration and increased citations

- maximum visibility for your research: over $100 \mathrm{M}$ website views per year

At BMC, research is always in progress.

Learn more biomedcentral.com/submissions 